\title{
Replication of micro and nano-features on iPP by injection molding with fast cavity surface temperature evolution
}

Speranzaa, Vito ; Liparotia, Sara ; Calaon, Matteo; Tosello, Guido; Pantania, Roberto; Titomanlio, Giuseppe

Published in:

Materials \& Design

Link to article, DOI:

10.1016/j.matdes.2017.08.016

Publication date:

2017

Document Version

Peer reviewed version

Link back to DTU Orbit

Citation (APA):

Speranzaa, V., Liparotia, S., Calaon, M., Tosello, G., Pantania, R., \& Titomanlio, G. (2017). Replication of micro and nano-features on iPP by injection molding with fast cavity surface temperature evolution. Materials \& Design, 133, 559-569. https://doi.org/10.1016/j.matdes.2017.08.016

\section{General rights}

Copyright and moral rights for the publications made accessible in the public portal are retained by the authors and/or other copyright owners and it is a condition of accessing publications that users recognise and abide by the legal requirements associated with these rights.

- Users may download and print one copy of any publication from the public portal for the purpose of private study or research.

- You may not further distribute the material or use it for any profit-making activity or commercial gain

- You may freely distribute the URL identifying the publication in the public portal 


\section{Accepted Manuscript}

Replication of micro and nano-features on iPP by injection molding with fast cavity surface temperature evolution

Vito Speranza, Sara Liparoti, Matteo Calaon, Guido Tosello, Roberto Pantani, Giuseppe Titomanlio

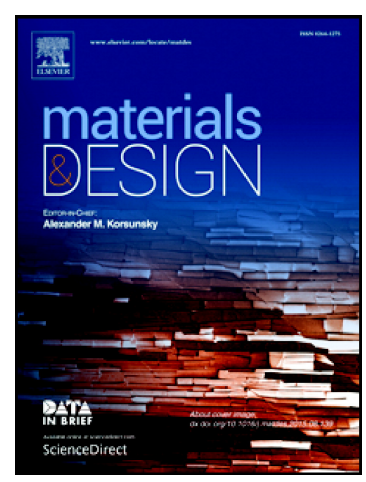

PII: S0264-1275(17)30762-1

DOI: doi: 10.1016/j.matdes.2017.08.016

Reference: JMADE 3275

To appear in: Materials \& Design

Received date: $\quad 20$ June 2017

Revised date: $\quad 4$ August 2017

Accepted date: $\quad 5$ August 2017

Please cite this article as: Vito Speranza, Sara Liparoti, Matteo Calaon, Guido Tosello, Roberto Pantani, Giuseppe Titomanlio, Replication of micro and nano-features on iPP by injection molding with fast cavity surface temperature evolution, Materials \& Design (2017), doi: 10.1016/j.matdes.2017.08.016

This is a PDF file of an unedited manuscript that has been accepted for publication. As a service to our customers we are providing this early version of the manuscript. The manuscript will undergo copyediting, typesetting, and review of the resulting proof before it is published in its final form. Please note that during the production process errors may be discovered which could affect the content, and all legal disclaimers that apply to the journal pertain. 


\section{Replication of micro and nano-features on iPP by injection molding with fast cavity surface temperature evolutions.}

Vito Speranza $^{a}$, Sara Liparoti ${ }^{a *}$, Matteo Calaon $^{b}$, Guido Tosello $^{b}$, Roberto Pantani $^{a}$, Giuseppe Titomanlio $^{a}$

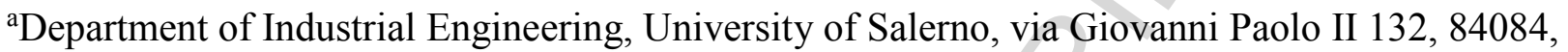
Fisciano (SA), Italy.

${ }^{b}$ Department of Mechanical Engineering, Technical University of Denmark, Lyngby, Denmark

*sliparoti@unisa.it 


\title{
Replication of micro and nano-features on iPP by injection molding with fast cavity surface temperature evolutions.
}

\begin{abstract}
The production of polymeric components with functional structures in the micrometer and submicrometer range is a complex challenge for the injection molding process, since it suffers the use of low cavity surface temperatures that induce the fast formation of a frozen layer, thus preventing accurate replication of micro and nano-features.

In this work, a thin heating device allowed reaching and maintaining the desired temperature on the cavity surface, by joule effect. A nickel insert with micro and nano-features in relief was located on the cavity surface, and the replication by isotactic polypropylene of the features was analyzed, by Atomic Force Microscopy, under several process parameters. The increase of holding pressure enhanced the replication, but accurate replication was achieved only increasing the cavity surface temperature. A heating time comparable with cavity filling time was sufficient to obtain accurate replication, with adequate surface temperatures.

In the case of nano-features, the replication accuracy was affected by the morphology developed on the molding surface, that is aligned along the flow direction with dimensions comparable with the dimension of the nano-features. Therefore, their formation on the surface reduced the accuracy of replication in the direction orthogonal to the flow front.
\end{abstract}

Keywords: injection molding, replication, polypropylene, mold temperature, cavity surface temperature

\section{Introduction}

Injection molding is one of the major processes to produce polymeric parts. Recently, many efforts have been devoted to produce polymeric components having micro-features, because the demands for micro-electromechanical systems (MEMS) applicable to the life science fields, such as DNA sequencing and clinical diagnostics devices, continuously increase. Moreover, the possibility to 
replicate micro and nano-features on polymeric components allows to control the surface properties of the objects. For instance, the modification of tribological properties is of particular interest in the cases in which coatings are not allowed (Lee et al., 2004) such as in medical technology, where the local wetting of the surface could influence the effectiveness (Kuhn et al., 2010) of the devices.

Different processes were proposed to produce polymeric micro and nano-structured surfaces. One of these is the hot embossing process, in which the polymeric part is heated above its transitional temperature to ensure the replication of the features (Kimerling et al., 2006; Shao et al., 2006). This technology was adopted also for the production of micro and nano-structured surfaces in semicrystalline polymers (Leech, 2008). The roll-to-roll embossing was also proposed for the production of micro-structured surfaces (Velten et al., 2011; Zhang et al., 2015). However, in both processes, the polymer detained amount of internal stress that could prevent an accurate replication (Schift et al., 2000). A more accurate replication of micro and nano-features on polymeric surface could be obtained by nanoimprinting (Kooy et al., 2014; Tan et al., 2014); however, this process is generally expensive and not suitable for mass production.

Despite the wide areas in which the micro and nano-structured surfaces could be applied, their production can be difficult using the conventional injection molding process. The difficulties are mainly due to the so-called "hesitation effect" (Attia et al., 2009; Yao, 2002): when polymer melt is injected, it tends to fill the mold cavity where the resistance to the flow front is lower, therefore, the flow stagnates, namely "hesitates" (Surace et al., 2012), at the entrance of microscopic patterns. If the mold temperature is low, the polymer solidifies before the micro-features are completely filled: it may be strategic to control the mold temperature during the process.

Different systems were proposed to control cavity surface temperature during the injection molding stages. Yao and Kim reported a rapid cavity surface temperature variation by coating the mold with an electrically conductive layer, which allows to heat the mold by joule effect (Yao et al., 2006). Similar systems were adopted by other authors, such as Jansen and Pantani (De Santis and Pantani, 2016; Jansen and Flaman, 1994). Chen et al. proposed induction heating of a mold plate to raise the mold temperature (Chen et al., 2008; Lin et al., 2012) Saito and Sato used the direct infrared heating on the polymer to control the mold surface temperature (Saito et al., 2002; Sato et al., n.d.).

The systems proposed to control mold temperature evolution were often tested also to enhance the replication of micro and nano-features on polymeric molded parts and the findings confirmed that the increase of mold surface temperature can enhance the replication accuracy of micro and nanometric parts (Matschuk and Larsen, 2013). Some authors adopted variothermal systems to improve the replication-ability of the amorphous polymers during the injection molding process (Kalima et al., 2007; Kuhn et al., 2010; Zhou et al., 2017). They generally concluded that the replication is 
strongly dependent on the mold temperature and on the time the temperature is kept high. Holding pressure and holding time seem to have a less significant effect. However, being the heating rate of the variothermal systems below $10^{\circ} \mathrm{C} / \mathrm{s}$, the cooling that takes place after the heating stage is also slow. Therefore, the processing time substantially increases and becomes not comparable with the processing times of conventional injection molding, as also concluded by Gadegaard and coworkers (Stormonth-Darling et al., 2016). Yu et al. applied infrared heating to the replication of microfeatures (Yu et al., 2007): they found that the micro-feature replication quality increases on increasing the heating time. Masato et al. analyzed the effect of mold temperature, trapped air and cavity thickness on the replication of polystyrene. To increase cavity surface temperature, they applied electrical heating cartridges below the cavity surface. They showed that the main parameters that affect the replication are mold temperature and cavity thickness (Masato et al., 2016). Thin electrical heaters were proposed by Liparoti et al. and succeeded in increasing the heating rate up to $60^{\circ} \mathrm{C} / \mathrm{s}$ and in reducing the cooling of cavity surface to few seconds (Liparoti et al., 2015). Thus, the processing time was comparable with the conventional injection molding process.

In this work, a fast mold temperature evolution was obtained by placing below the mold cavity surface a conductive layer made of poly(imide-amide) loaded carbon black, thermally and electrically insulated from the mold by kapton ${ }^{\circledR}$ layers. This heating device has some peculiar properties that makes it suitable to be adopted in injection molding process without significantly increasing the whole processing time. First of all, the heating rate is high enough to allow the achieving of the selected cavity surface temperature during the injection stage, before the melt comes in contact with the cavity wall during the injection stage. The power control allows keeping constant the temperature on the cavity surface for the desired time, and thanks to the small heating device thickness, a very fast cooling of the cavity surface is also possible. Therefore, the ejection of the molded can take place at very low temperature. The injection molding coupled with the fast mold temperature evolution system is tested on an isotactic polypropylene (iPP) with the aim of investigating the effect of the process parameters, such as packing pressure, cavity surface temperatures, heating times, on the replication of micro and nano-features.

\section{Experimental}

The polypropylene (iPP), with the commercial name T30G, adopted for the injection molding tests was supplied by Basell (non-nucleated, $\mathrm{Mw}=376,000, \mathrm{Mw} / \mathrm{Mn}=6.7$, tacticity=87.6\%). The crystallization kinetics and the rheological characterization is reported elsewhere (De Santis et al., 2006; Pantani et al., 2014; Sorrentino and Pantani, 2013). Micro-heaters made of a poly(amide- 
imide)/carbon back compound, with a thickness of $50 \mu \mathrm{m}$ and a sheet resistance of $40 \Omega /$ square, were used for conditioning the mold surface temperature by Joule effect (Liparoti et al., 2016a).

The nano and micro-features produced for this work were created on nickel shim insert; the procedure for fabricating the master geometry is reported elsewhere (Calaon et al., 2013; Menotti et al., 2014). As shown in Figure 1, both the features have crossed wings made of ridges with a rectangular cross section. The micro-ridges have a constant nominal height of $5 \mu \mathrm{m}$ and width of 20 $\mu \mathrm{m}$, whereas the nano-ridges have crossed wings with a nominal height of $60 \mathrm{~nm} \pm 3 \mathrm{~nm}$ and width of $500 \mathrm{~nm}$. The crosses are positioned in the center of the $19 \mathrm{~mm}$ x $19 \mathrm{~mm}$ nickel shim insert.
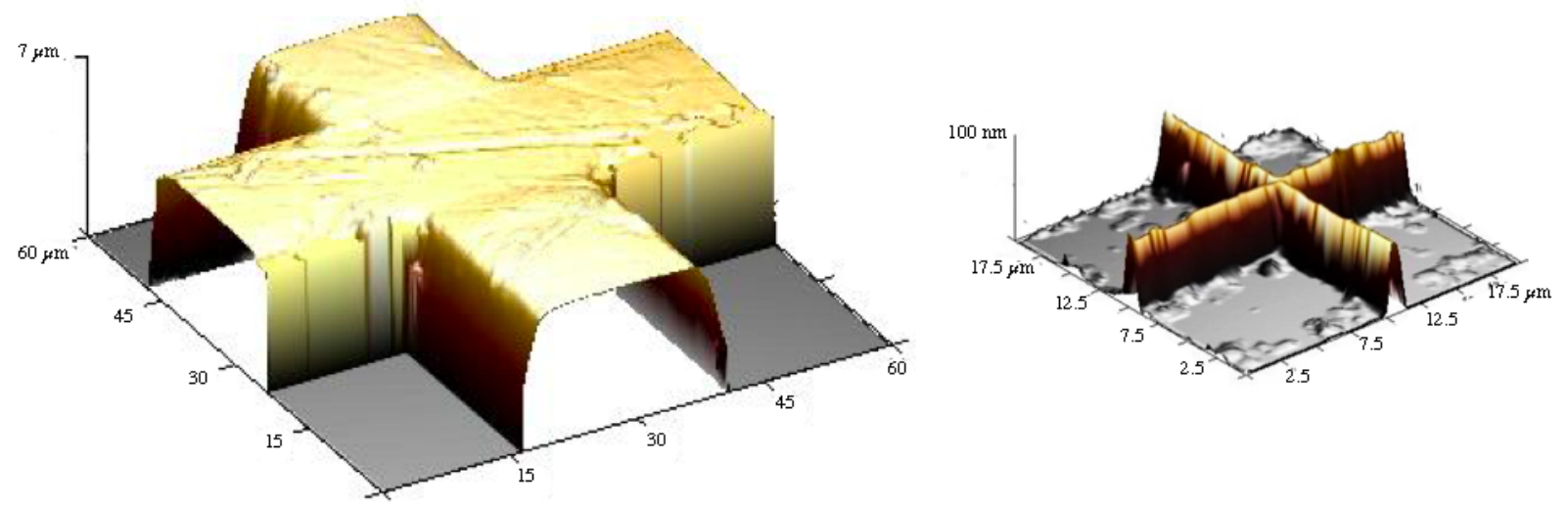

(a)

Figure 1 AFM acquisitions of micro and nano-features located on the nickel shim (a) height $5 \mu \mathrm{m}$ width $20 \mu \mathrm{m}$; (b) height $60 \mathrm{~nm}$ width $500 \mathrm{~nm}$.

The mold contained a rectangular cavity with a length of $110 \mathrm{~mm}$, width of $12.7 \mathrm{~mm}$, and thickness of $1.5 \mathrm{~mm}$; the gate had a thickness of $0.5 \mathrm{~mm}$ (Figure 2). As shown in Figure 2a, the nickel shim was inserted at the gate end of the cavity. Steel layers having a thickness of $0.4 \mathrm{~mm}$ were layered on both sides of the cavity, in the part left free by the nickel shim. Two micro-heaters, one on each side of the cavity, were placed between the mold wall and nickel shim/steel layer. These micro-heaters, made of a $50-\mu \mathrm{m}$-thick poly(amide-imide)/carbon black compound, had a sheet resistance of 40 $\Omega /$ square and were used for conditioning the cavity surface temperature by Joule effect (Liparoti et al., 2016a). In particular, the heating elements is the poly(amide-imide)/carbon black compound and this heater is electrically insulated from the mold by a $20 \mu \mathrm{m}$ thick poly(amide-imide) layer. Another poly(amide-imide) layer of $120 \mu \mathrm{m}$ thickness was added to reduce the heat loss toward the mold. The mold was equipped with four pressure transducers positioned just before the gate (P1) and three points along the flow path (P2-P4) as shown in Figure 2b. Additional pressure transducer is located in the injection chamber, named position P0. A temperature sensor (thermocouple type T, OMEGA) was located on the cavity surface $20 \mathrm{~mm}$ downstream of the gate. 

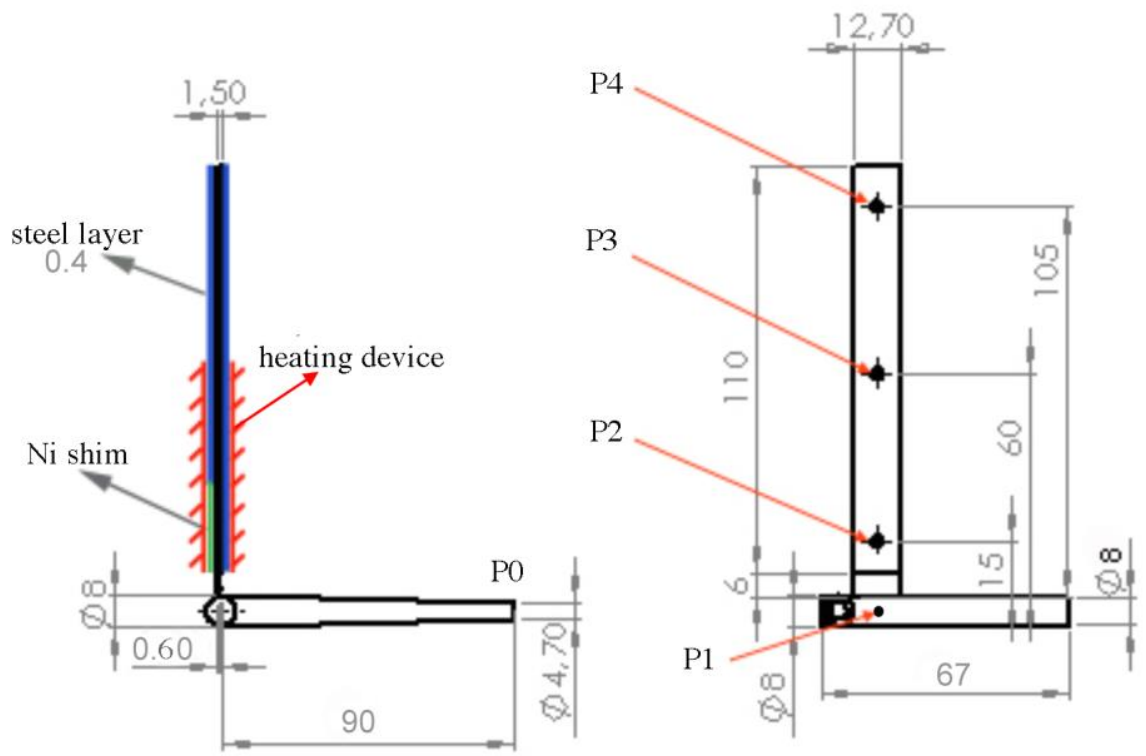

Figure 2 Sketch of the cavity geometry and of the nickel shim position in the cavity.

Molded samples were produced using a 70-ton Negri-Bossi reciprocating screw injection molding machine. All molding trials were performed with a constant flow rate at $2.8 \mathrm{~cm}^{3} / \mathrm{s}$ (that gave rise to a filling time of about $0.8 \mathrm{~s}$ ), a holding time of $8 \mathrm{~s}$, an injection temperature of $220^{\circ} \mathrm{C}$. The whole mold was conditioned and kept at $30^{\circ} \mathrm{C}$. Trials were carried out adopting three electrical power densities to the heating device $\left(4,7\right.$, and $\left.10 \mathrm{~W} / \mathrm{cm}^{2}\right)$, for different times $\left(\mathrm{t}_{\mathrm{h}}\right)$ after the first contact of melt in position $\mathrm{P} 2(1.3 \mathrm{~s}, 8 \mathrm{~s}$, and $13 \mathrm{~s}$, respectively). The other operating conditions are summarized in Table 1 . In this table, $\mathrm{P}_{\mathrm{e}}$ is the electrical power applied; $\mathrm{T}_{\text {level }}$ is the temperature reached on the steel layer (cavity surface temperature); $t_{h}$ is the time that the heater is kept active; $t_{a}$ is the time that the heater was activated before the contact with the polymer in $\mathrm{P} 2$; and $\mathrm{P}_{\text {hold }}$ is the holding pressure. The names of the experiments are coded taking into account the selected cavity surface temperature, the heating time and the holding pressure for the cases in which the heating devices are active. For instance, a code 90-8-720 identifies a test carried out with a cavity surface temperature of $\mathrm{T}_{\text {level }}=90^{\circ} \mathrm{C}$, kept for a time of $t_{h}=8 \mathrm{~s}$ and a holding pressure of $\mathrm{P}_{\text {hold }}=720 \mathrm{bar}$. The experiments in which the heaters are not active are named passive 360 and passive 720 , to indicate the holding pressure adopted. 
Table 1 Operating condition selected for the injection molding tests at different heating powers, heating times and holding pressures (where $P_{e}=$ electrical power applied; $T_{\text {level }}=$ temperature reached on the steel layer; $t_{h}=$ time that the heater is kept active; $t_{a}=$ time that the heater was activated before the contact with the polymer in P2; Phold=holding pressure)

\begin{tabular}{cccccc}
\hline Test run & $\begin{array}{c}\mathbf{P}_{\mathbf{e}} \\
\left(\mathbf{W} / \mathbf{c m}^{2}\right)\end{array}$ & $\begin{array}{c}\mathbf{T}_{\text {level }} \\
\left({ }^{\mathbf{C}} \mathbf{C}\right)\end{array}$ & $\mathbf{t}_{\mathbf{h}} \mathbf{( s )}$ & $\mathbf{t}_{\mathbf{a}} \mathbf{( s )}$ & $\mathbf{P}_{\text {hold }}$ \\
\hline passive360 & 0 & 30 & 0 & 0 & 360 \\
passive720 & 0 & 30 & 0 & 0 & 720 \\
$90-8-720$ & 4 & 90 & 8 & 4 & 720 \\
$90-13-720$ & 4 & 90 & 13 & 4 & 720 \\
$120-1-360$ & 7 & 120 & 1.3 & 4 & 360 \\
$120-8-360$ & 7 & 120 & 8 & 4 & 360 \\
$120-13-360$ & 7 & 120 & 13 & 4 & 360 \\
$120-1-720$ & 7 & 120 & 1.3 & 4 & 720 \\
$120-8-720$ & 7 & 120 & 8 & 4 & 720 \\
$120-13-720$ & 7 & 120 & 13 & 4 & 720 \\
$150-1-360$ & 10 & 150 & 1.3 & 4 & 360 \\
$150-8-360$ & 10 & 150 & 8 & 4 & 360 \\
$150-13-720$ & 10 & 150 & 13 & 4 & 360 \\
$150-1-720$ & 10 & 150 & 1.3 & 4 & 720 \\
$150-8-720$ & 10 & 150 & 8 & 4 & 720 \\
$150-13-360$ & 10 & 150 & 13 & 4 & 720 \\
\hline
\end{tabular}

\section{Atomic force microscope}

The micro and nano-features replication on the surface of injection molded samples were observed by Atomic Force Microscope, AFM. Micro-graphs were collected in air at room temperature with a Dimension 3100 coupled with a Bruker Nanoscope V controller operating in contact mode. Commercial probe tips with nominal spring constants of $1-5 \mathrm{Nm}$, a tip with radius of 8-12 nm and height of 10-15 $\mu \mathrm{m}$ was adopted.

Due to the AFM measuring principle, resulting topography includes features of both the measured sample and the probe shape. In particular, the selected probe is asymmetric with front and back angle of $25^{\circ}$ and $15^{\circ}$ respectively; furthermore, the cantilever is tilted of $17^{\circ}$ with respect to the sample plane, the tilted angle increases the probe front angle and decreases the probe back angle. The interaction between the sample and the probe introduces distortions, which reduce the image quality and increase the uncertainty in the quantitative evaluation. The so-called convolution effect is particularly evident whenever structures with sharp details are measured in the micrometer range, where the direct consequence is the lack of data in correspondence of the inaccessible regions, in proximity of steep slopes, narrow cavities, undercuts or hidden parts (Marinello, 2007). In the case proposed in this work, the AFM topographical descriptions of the feature replications on the molding surface were affected by tip geometry, as schematized in Figure 3. 


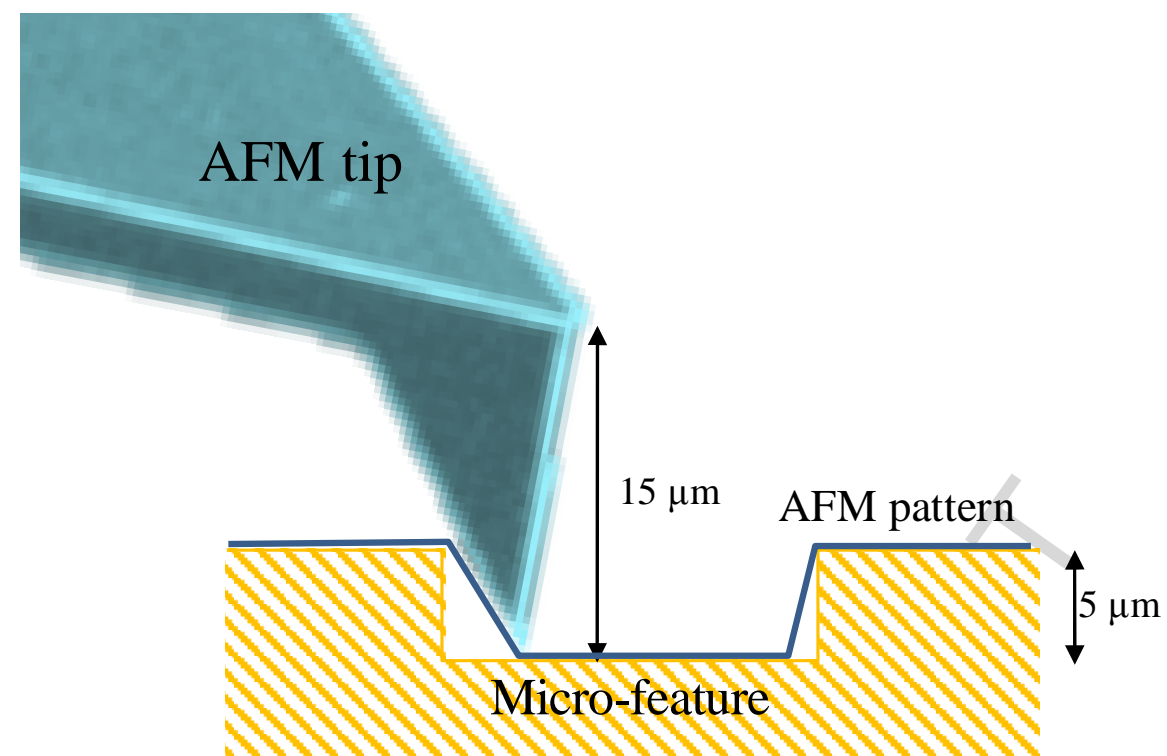

Figure 3 Sketch on the possible interaction between the AFM probe and the micro-feature: the reported AFM pattern is due to the convolution between tip shape and sample profile.

Some methods to reduce the effect due to the interaction between the tip and the sample are reported in the literature (Calaon et al., 2013). In this paper, to reduce the effect due to asymmetry of the tip, two acquisitions were performed for each sample, rotating the sample of $180^{\circ}$ after the first acquisition. Moreover, at least five samples per condition were analyzed in order to obtain the standard deviation of each condition.

The replication of the micro-features was analyzed starting from the AFM acquisition. Each experimental pattern was derived and each peak was fitted using the following equation:

$y=y_{0}+A \frac{1}{1+e^{-\frac{x-x_{c}+w_{1} / 2}{w_{2}}}}\left(1-\frac{1}{1+e^{-\frac{x-x_{c}-w_{1} / 2}{w_{3}}}}\right)$

where $\mathrm{y}_{0}=$ offset, $\mathrm{x}_{\mathrm{c}}=$ center, $\mathrm{A}=$ amplitude, $\mathrm{w}_{1}=$ full width of half maximum, $\mathrm{w}_{2}$ and $\mathrm{w}_{3}$ are parameters that take into account the asymmetry of the calculated distribution with respect to the center $\mathrm{x}_{\mathrm{c}}$. Figure 4 shows an example of the cross profile obtained from AFM height images, the absolute value of the first derivative of this profile and the fitting of the curve by equation (1). 


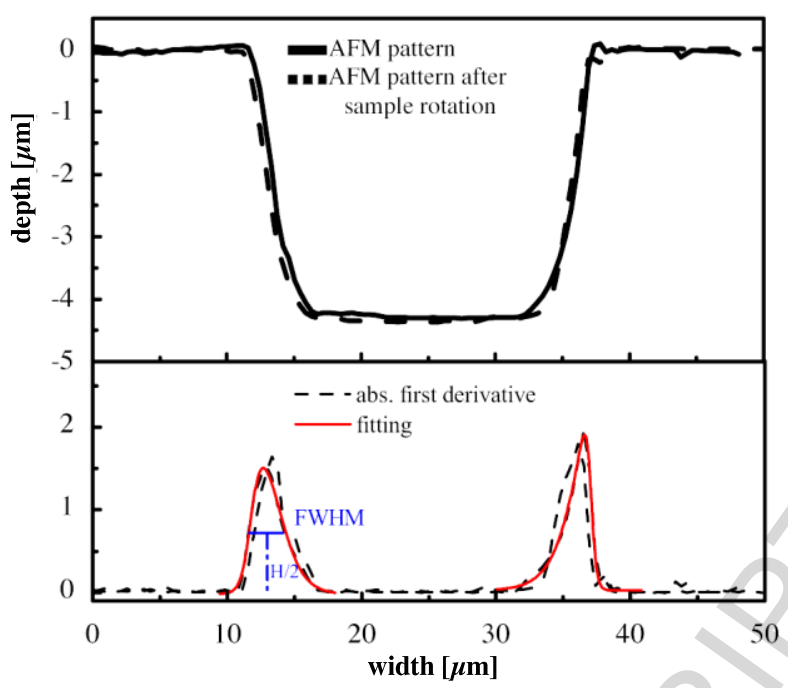

Figure 4 (upper) Example of AFM pattern for the sample 150-13-720. In the figure is reported also the AFM pattern acquired rotating the sample of $180^{\circ}$ (dashed line). (bottom) Absolute first derivative of the AFM pattern and fitting obtained adopting eq. 1 .

The full width at half maximum of the fitting curve (FWHM) was chosen as replication quality index, as also suggested in literature (Hoon et al., 2008; Kang, 2012). The FWHM was measured also for the shim and compared with the FWHM measured on the molded objects.

A different replication index was adopted with nano-features. In particular, the nano-feature height, $h$, was adopted in these cases, as already proposed in literature (Calaon et al., 2013). The percentage deviation of the feature height $(h)$, measured on the features replicated on the molded sample, from the height of the nickel insert $(60 \pm 3 \mathrm{~nm})$ was indicated as $\mathrm{H}$, according to equation (2).

$H=\frac{h_{\text {nickel }}-h_{P P}}{h_{\text {nickel }}} * 100$

$h_{P P}$ and $h_{\text {nickel }}$ are the heights measured by AFM on the molded sample and on the nickel insert, respectively.

\section{Results and discussion}

\section{Pressure and temperature evolutions}

The replication quality is influenced by the injection molding conditions such as packing pressure, cavity surface temperature and its temperature evolution. As summarized in Table 1 all these parameters were investigated in the present study. 


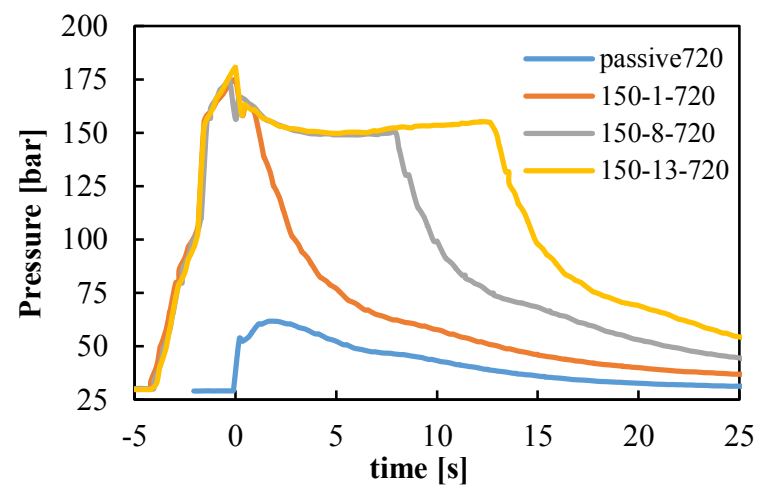

Figure 5 Temperature evolutions of the experiments performed with $P_{h}=720$ bar, $T_{\text {level }}=150^{\circ} \mathrm{C}$ and different heating times $t_{h}(150-1$ 720, 150-8-720 and 150-13-720). Temperature evolution of the experiment passive 720 is also reported for comparison.

Figure 5 shows cavity surface temperature evolutions during experiments performed with a $\mathrm{P}_{\mathrm{h}}=720$ bar and $\mathrm{T}_{\text {level }}=150^{\circ} \mathrm{C}$ held for heating times of $1.3,8$, and 13 seconds. Temperature evolution carried out without activating the heaters (experiment passive720) is also reported for comparison. In Figure 5, $\mathrm{t}=0 \mathrm{~s}$ corresponds to the time at which the melt reaches position $\mathrm{P} 2$ inside the cavity (Figure 2). For $t<0 s$, the temperature increase is due to the joule effect induced by activation of the heating device. For $t>0 \mathrm{~s}$, up to the heating time $t_{h}$, the surface temperature decreases down to the value set by the heating device. When the heater is deactivated $\left(t>t_{h}\right)$, the temperature decreases toward the temperature of the mold. It is interesting to note that the surface heating stage starts with the screw movement, during that time the melt fills the sprue and the runner. The temperature can be kept constant for the desired time and the cooling time is only slightly increased by the heating process (see the Supporting material).

Generally, the pressure evolution depends on the cavity surface temperature evolution (Liparoti et al., 2016b). Figure 6 shows pressure evolutions obtained for several tests. The pressure evolutions for the experiments performed without activating the heating devices, named passive 360 and passive 720, are also reported in Figure 6a and c for comparison. 

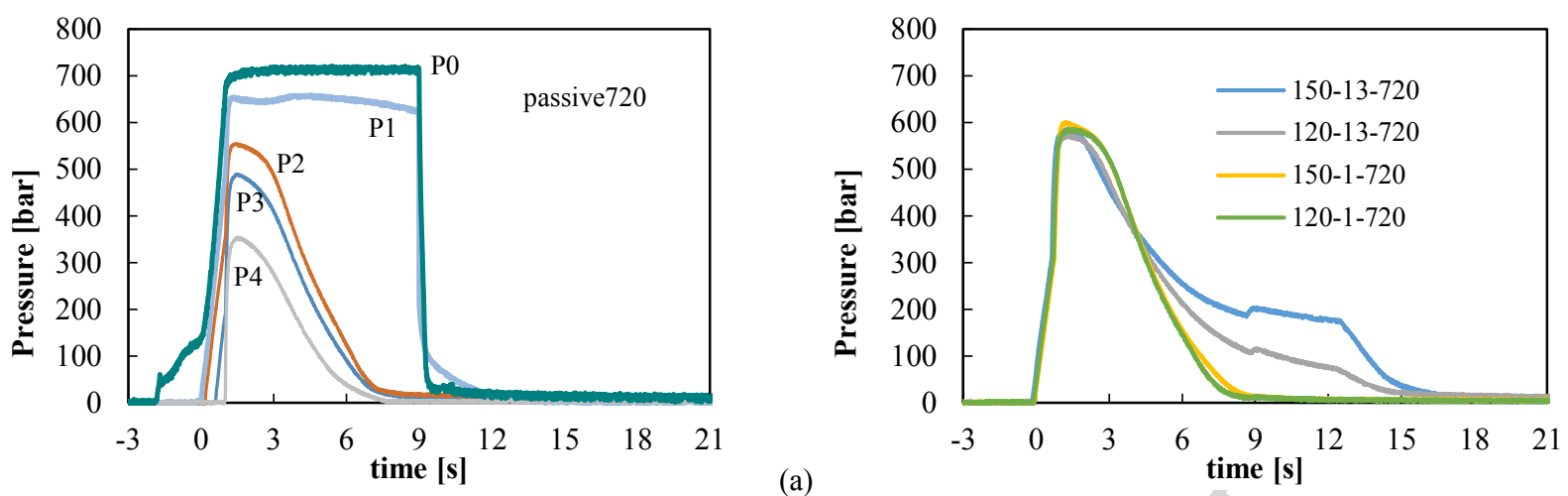

(b)
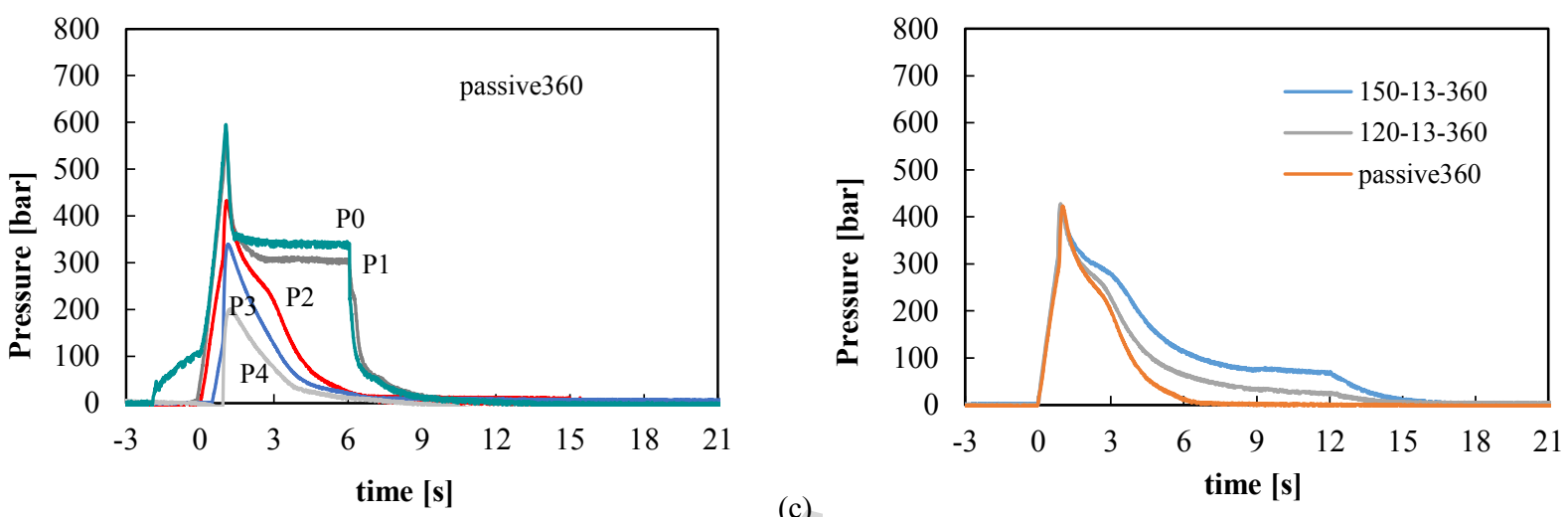

(c)

Figure 6 Pressure evolutions obtained for the test performed without activating the heater passive720 (a), and pressure evolutions in pos. P2 obtained activating the heater with different heating powers and heating times with a holding pressure of 720 bar (b). Pressure evolutions obtained for the test performed without activating the heater passive 360 (c), and pressure evolutions in pos. P2 obtained activating the heater with different heating powers with a holding pressure of 360 bar (d).

Figure $6 \mathrm{a}$ shows the pressure evolutions, for the passive720 case, in different positions P0-P4 along the flow path (see Figure 2). Pressure evolutions allow to identify the three main stages of injection molding process: filling, packing/holding and cooling. Pressure undergoes a fast increase in all positions during the cavity filling that is $0.8 \mathrm{~s}$ long. After cavity filling, the pressure (holding pressure) is kept constant in position $\mathrm{P} 0$ for a certain time to allow additional feeding of melt into the cavity (the packing flow), to compensate for the shrinkage due to the polymer cooling and crystallization determined by the contact of melt with the cavity surface. The packing flow ends when the gate, that is the thinner part upstream the cavity, solidify: this corresponds to the slightly pressure increase, from 640 bar to 660 bar $(t=3.2 \mathrm{~s}$ ), in position P1 (Kamal et al., 2009). After the gate sealing, no melt can enter inside the cavity and the pressures in the cavity P2-P4 start to decrease faster. The pressure in position P0 and P1 undergoes a sharp decrease when the pressure in released by the machine. Figure 6c shows pressure evolutions for the passive 360 case. The main difference with respect to the case passive720 is the sharp pressure decrease at the end of filling, due to the fact that the selected holding pressure (360 bar) is smaller than the pressure at the end of the filling step. The pressure evolutions in position P2, measured during the experiments performed keeping active the heating devices are reported in Figure $6 \mathrm{~b}$ and $\mathrm{d}$. If the heating device is activated 
for times longer than the gate sealing time, pressure in pos. P2 decreases to zero into two steps: during the first step, the heaters are still active and the pressure reaches a constant value that depends on the cavity surface temperature adopted; at the heating device deactivation $\left(\mathrm{t}=\mathrm{t}_{\mathrm{h}}\right)$, the pressure undergoes another step down, which, for the test considered in this work, allows reaching zero. If the heating devices are active for time $t_{h}$ smaller than the gate sealing time, the two pressure steps overlaps (Liparoti et al., 2016b).

\section{Replication of microfeatures}

Figure 7 shows the AFM height maps acquired on the samples obtained without activating the heating device and with 360 bar and 720 bar holding pressure (passive360 and passive720); the pattern acquired on the nickel insert is also reported for comparison. The crosses on the nickel insert are in relief and thus produce grooves on the surface of the molded samples. A holding pressure increase, from 360 to 720 bar, induced a significant improvement of replication, as described in the literature (Yoshii et al., 1998). However, even if the heights of the grooves were close to the height of the nickel relief, the grooves did not show sharp edges. Therefore, the replication was surely not accurate in the passive cases.

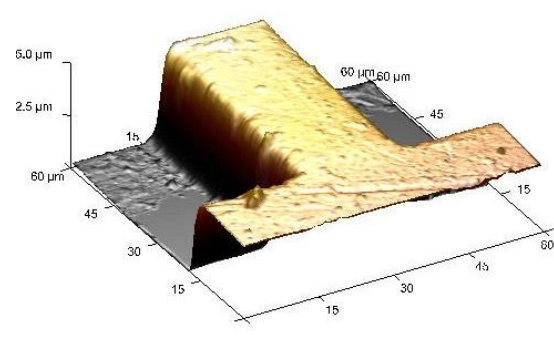

nickel insert

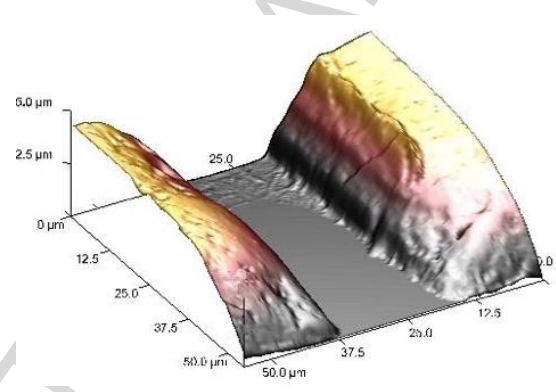

passive 360

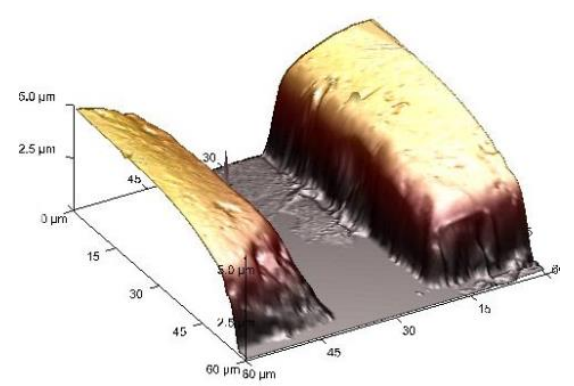

passive 720

Figure 7 AFM height image. From left to right are reported profiles of the nickel insert, of the sample obtained with $P_{h}=360$ bar and $P_{h}=720$ bar.

A significant improvement of replication was achieved with cavity surface temperature higher than the temperature of the conditioned mold $\left(30^{\circ} \mathrm{C}\right)$. Figure 8 shows AFM height maps of the samples obtained with different temperature evolutions. Also in these cases, the heights of the replicated features were close to the height of the nickel relief with a small deviation, i.e. $\pm 0.05 \mu \mathrm{m}$. The comparison between Figure 7 and Figure 8 shows that the edges were sharper with respect to the passive cases on increasing cavity surface temperature. In particular, a significant improvement of the replication was achieved already keeping active the heater for a few tenths of a second after filling $\left(t_{h}=1.3 \mathrm{~s}\right)$, with $120^{\circ} \mathrm{C}$ and $150^{\circ} \mathrm{C}$ cavity surface temperature. 


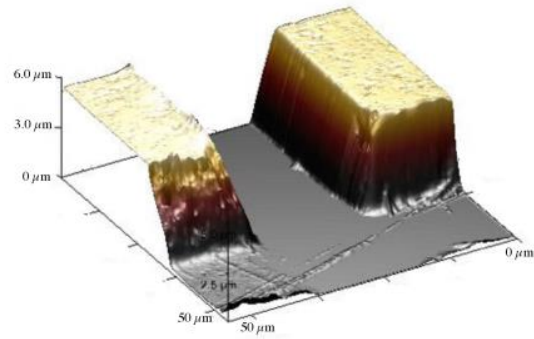

120-1-360

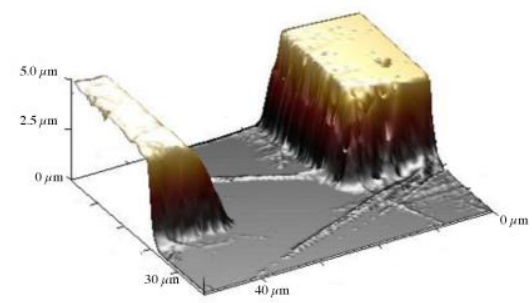

150-1-360

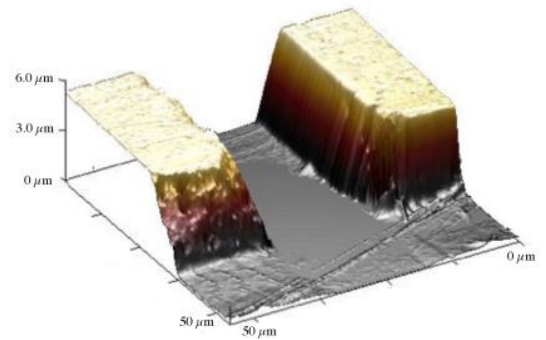

120-13-360

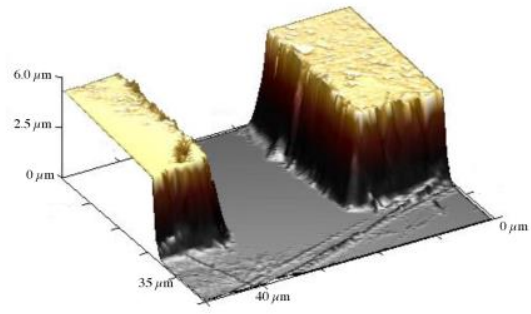

$150-13-360$

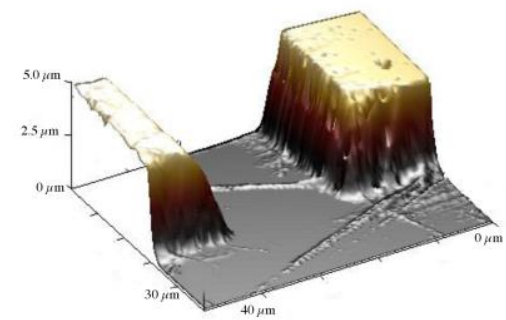

$120-13-720$

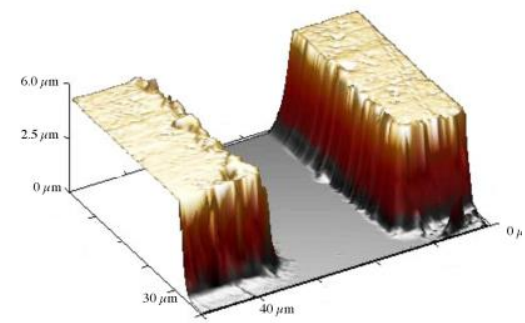

$150-13-720$

Figure 8 AFM height images of the micro-features on injection molded samples obtained in different conditions of holding and cavity surface temperature.

A quantitative evaluation of the replication quality was conducted by analyzing the AFM patterns, as reported in the "Methods" section, and calculating the FWHM index. Figure 9 summarizes the replication quality in term of FWHM index obtained for all the molded samples listed in Table 1; the FWHM of the nickel insert is also reported for comparison.

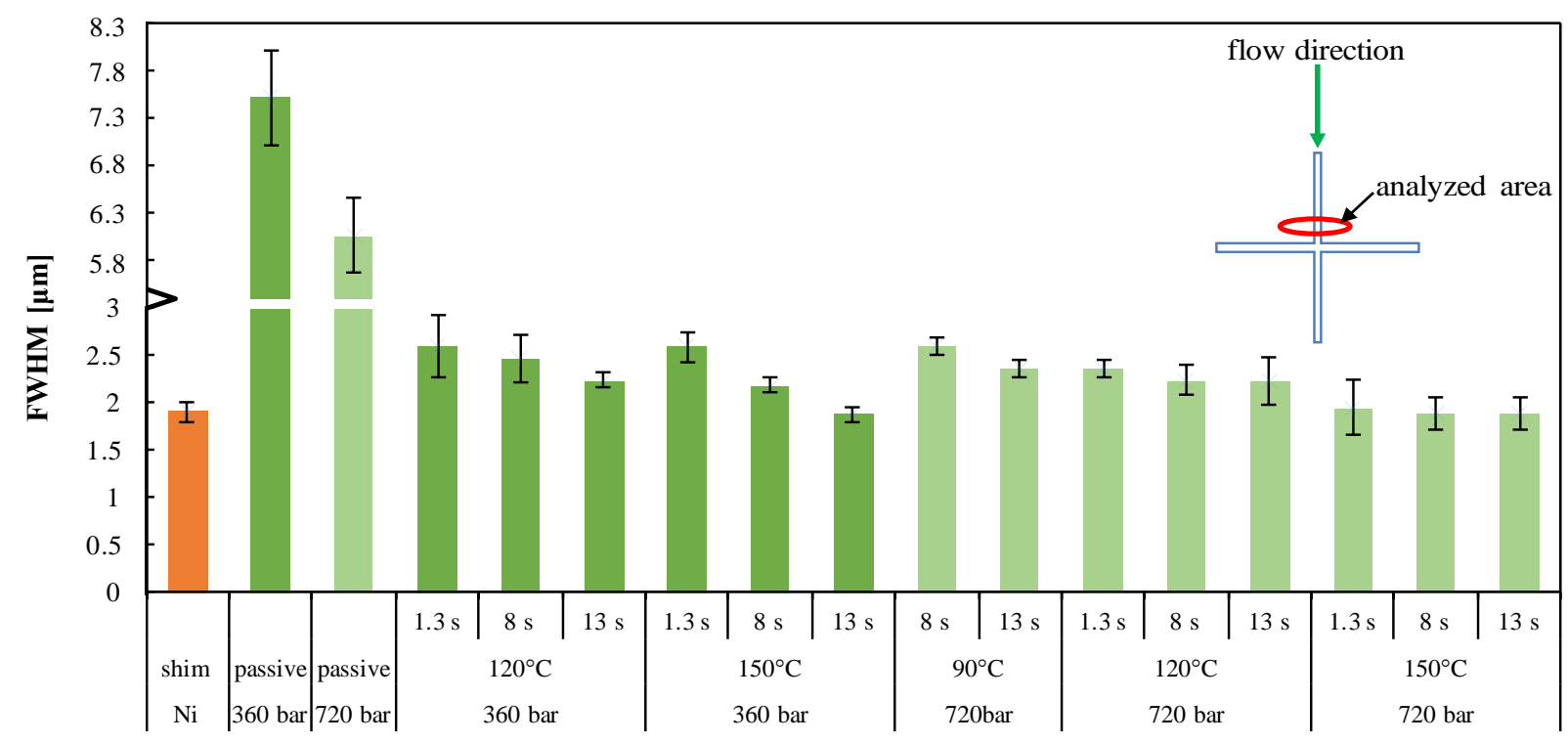

Figure 9 FWHM index of micro-feature aligned with the flow direction on samples obtained as indicated in Table 1. A sketch of the area where the AFM patterns have been acquired is also reported

A comparison between the two passive cases shows that the increase of holding pressure from 360 bar to 720 bar induced a significant enhancement of the replication, FWHM reduced from 7.1 
to $5.6 \mu \mathrm{m}$. However, these values are far from the best value for FWHM, that is $1.9 \mu \mathrm{m}$ obtained for the micro-features on the nickel insert. A similar effect of holding pressure on the FWHM was observed also adopting high cavity surface temperature. In particular, with $t_{h}=1.3 \mathrm{~s}$ heating time and $\mathrm{T}_{\text {level }}=150^{\circ} \mathrm{C}$ the $\mathrm{FWHM}$ decreased from 2.6 to $1.9 \mu \mathrm{m}$ by increasing holding pressure from 360 bar to 720 bar. The effect of the increase of the holding pressure was significant in spite of the short heating time: with $t_{h}=1.3 \mathrm{~s}$ heating time the cavity surface temperature remains at values higher than $100^{\circ} \mathrm{C}$ for a time interval that is longer than the gate sealing time $(3 \mathrm{~s})$. Furthermore, during that time, the effect of holding pressure on pressure evolutions is very significant. Generally, a lower holding pressure prevents a good replication since the local pressures reach smaller values.

By increasing the heating time the FWHM decreases, especially when low holding pressure was adopted. This is due to the fact that the application of a high cavity surface temperature for longer times keeps the viscosity at low values and delays the decrease of local pressure to zero (see Figure 6), favoring a further filling of the feature during the time $t_{h}$ in which the heater is kept active. Adopting higher holding pressure the effect of the heating time on the replication was less significant. This is not a surprise for $\mathrm{T}_{\text {level }}=150^{\circ} \mathrm{C}$, since the FWHM reached the same value of the nickel insert already with $t_{h}=1.3 \mathrm{~s}$. For $\mathrm{T}_{\text {level }}=90^{\circ} \mathrm{C}$ and $120^{\circ} \mathrm{C}$ the replication accuracy was significantly lower with respect to the cases in which $\mathrm{T}_{\text {level }}=150^{\circ} \mathrm{C}$. This finding can be due to crystallization kinetics that are faster at those temperatures, since they are closer to the crystallization temperature of the adopted polymer, i.e. $80^{\circ} \mathrm{C}-100^{\circ} \mathrm{C}$ (Coccorullo et al., 2003; De Santis et al., 2006). Moreover, the temperature decrease induced an increase of relaxation time (Kamal et al., 2009), therefore the orientation becomes higher and this also favors the increase of crystallization kinetics.

A similar analysis was performed on the wings replicated in the direction orthogonal with respect to the direction of the flow front. The results are reported in Figure 10. 


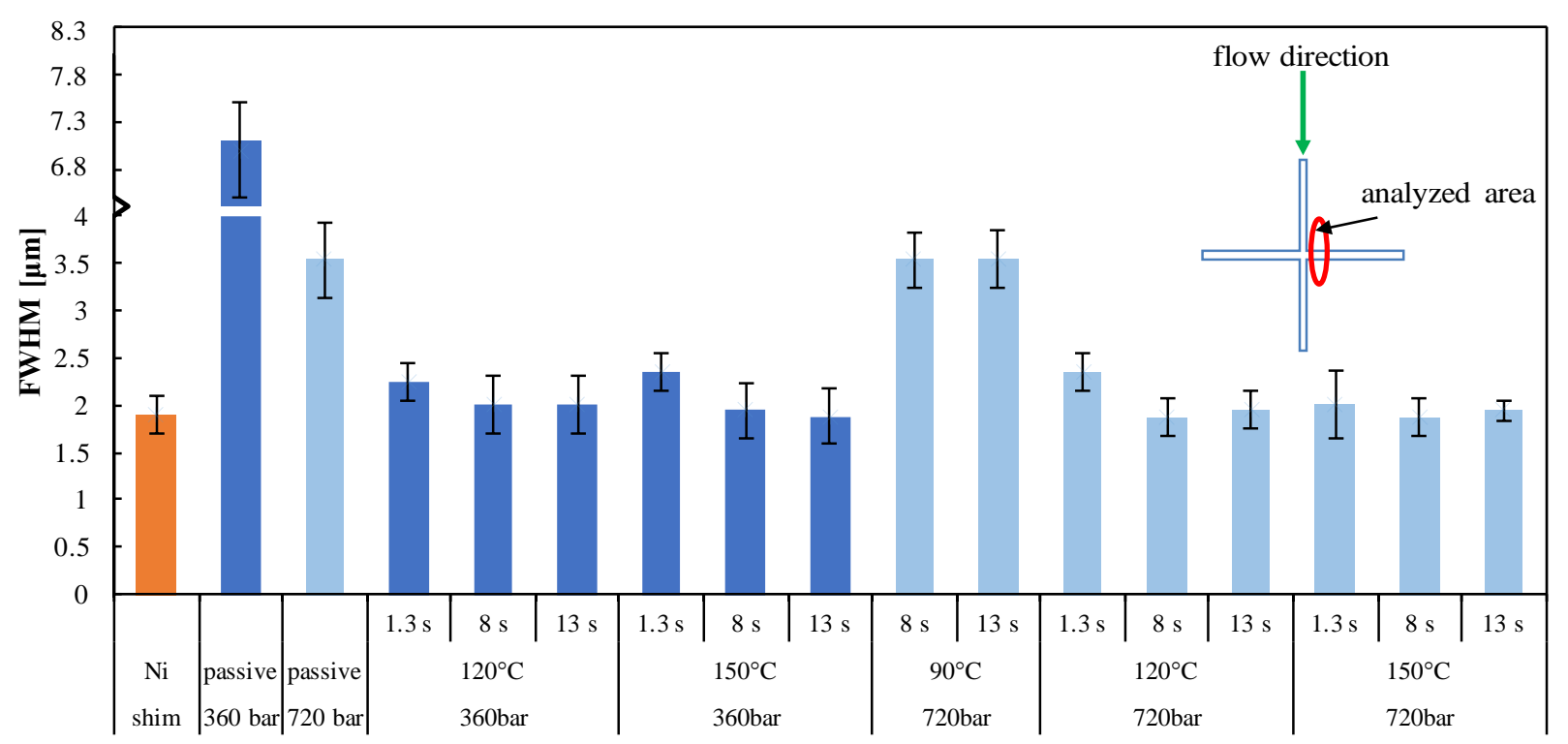

Figure 10 FWHM index of micro-feature orthogonal to the flow direction on samples obtained as indicated in Table 1. A sketch of the area where the AFM patterns have been acquired is also reported

By comparing Figure 9 and Figure 10, it results clear that the replication quality parameter (FWHM) as function of the cavity surface temperature, heating time and holding pressure on the wings aligned orthogonally to the direction of the flow front essentially reproduce the trends shown by the replication index in the direction parallel to the flow front. However, some differences can be detected in the values of FWHM with respect to the analysis carried out in the direction parallel to the flow front. In particular, the samples obtained with $\mathrm{T}_{\text {level }}=90^{\circ} \mathrm{C}$ show a higher FWHM for the wings aligned orthogonally to flow, whereas the values of FWHM calculated with $\mathrm{T}_{\text {level }}=120^{\circ} \mathrm{C}$ and $\mathrm{P}_{\mathrm{h}}=720$ bar seems to be more sensitive to the heating time.

It has to be mentioned that in this work a significant improvement of the replication was achieved with respect to the use of other heating/cooling systems. First of all, the height of the replicated micro-features was always close to the height of the nickel ridges, with a very small deviation, \pm $0.05 \mu \mathrm{m}$. The replication with injection molding assisted by other rapid heating/cooling systems resulted to be less accurate (Lucchetta et al., 2012; Yang et al., 2011). Moreover, adopting the heating system proposed in this work, with $\mathrm{T}_{\text {level }}=150^{\circ} \mathrm{C}$ and $\mathrm{P}_{\mathrm{h}}=720 \mathrm{bar}$, also the shape of the replicated feature was respected.

\section{Discussion on micro-features replication}

An interpretation can be given on the fact that replication quality of surface microstructures improves on increasing the holding pressure, the cavity surface temperature, and time in which the cavity surface temperature is kept high. Figure 11 represents a schematic view of melt filling a corner of the features in the nickel insert, where $\mathrm{P}(\mathrm{t})$ is the local pressure at a certain time. During the filling, the melt in contact with the cavity surface cools very fast and it may even solidify 
(Figure 11a); if this happens, even with high holding pressures, it may not be able to fill the microfeature (hesitation effect (Park et al., 2016)). The increase of cavity surface temperature reduces the thickness of the frozen layer and, for temperatures higher than the crystallization temperature, it can even prevent the formation of a frozen layer; this allows a better filling of the cavity (Figure 11b). If the frozen layer is formed, it is necessary to take into account also the elastic behavior of the material; in this case, the frozen layer could deform by the effect of pressure thus filling the nickel insert corner in a subsequent step. If the formation of the frozen layer is prevented by the effect of a high cavity surface temperature, the elastic behavior is less significant with respect to the viscous behavior. Furthermore, the increase of cavity surface temperature reduces the viscosity favoring the filling of the nickel insert corner
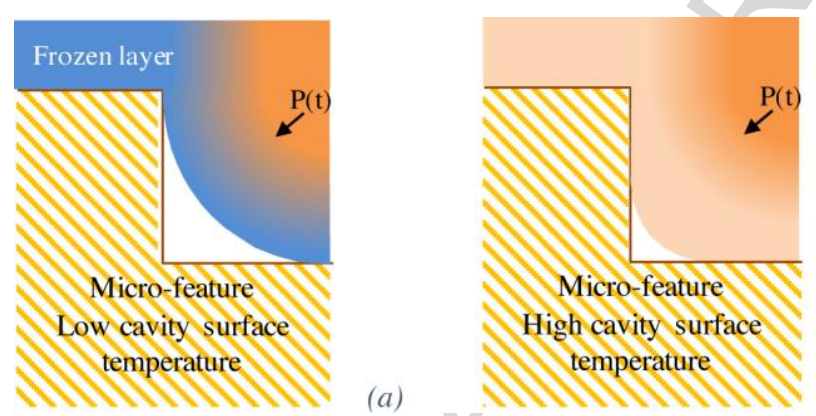

(a)

(b)

Figure 11 Schematic representation of the filling of nickel insert corner without activate the heating device (a) and activating the heating device (b). The blue color indicates the frozen layer, the orange one the melt. Intermediate status is shaded.

Obviously, also other effects can determine the replication quality. In this work, the polymer fills the nickel insert corner if the pressure exerted on it overcomes the pressure due to the trapped air, the pressure due to the surface tension (Mosaddegh and Angstadt, 2008) and the pressure due to the flow of the melt toward the corner. Under the isothermal condition hypothesis, assuming for air an ideal gas volumetric behavior, the pressure due to the trapped air, $\mathrm{P}_{\text {air, }}$ is:

$P_{\text {air }}=\frac{V_{\text {in }} P_{\text {in }}}{V_{\text {current }}}$

where $\mathrm{P}_{\text {in }}$ is the initial air pressure, $\mathrm{V}_{\text {in }}$ is the volume of the unfilled nickel insert corner, and $\mathrm{V}_{\text {current }}$ is its current volume. The current volume depends on the length of the features, $\mathrm{L}$, and on the unfilled cross-section, which is proportional to the square of the distance $\mathrm{d}(\mathrm{t})$ between the incoming polymer and the unfilled nickel insert corner shown in Figure $12 \mathrm{~b}$; thus, $\mathrm{P}_{\mathrm{air}}$, can be expressed as:

$P_{\text {air }} \propto \frac{V_{\text {in }}}{L d^{2}(t)}$

The capillary pressure, $\mathrm{P}_{\text {cap }}$, is proportional to the curvature of the interface between air and polymer. Equation (5) gives the capillary pressure for a surface with a generic curvature having radii $\mathrm{R}_{1}$ and $\mathrm{R}_{2}$; $\sigma$ is the surface tension.

$P_{\text {cap }}=\sigma\left(\frac{1}{R_{1}}+\frac{1}{R_{2}}\right)$ 
For the features discussed in this paper, the shape of the melt in contact with the cavity surface can be approximated to a cylinder, as shown in Figure $12 \mathrm{~b}$; therefore, $\mathrm{R}_{2}$ is infinite and the Equation (5) becomes Equation (6):

$P_{\text {cap }}=\frac{\sigma}{R_{1}}$

where $\mathrm{R}_{1}$ is related to the distance $\mathrm{d}(\mathrm{t}), d(t)=R_{1}(\sqrt{2}-1)$ (see Figure $12 \mathrm{~b}$ ).

In Figure 12 the capillary pressure and the pressure due to the trapped air are reported in function of $d(t)$; the surface tension was calculated according with Rytka et al (Rytka et al., 2016).
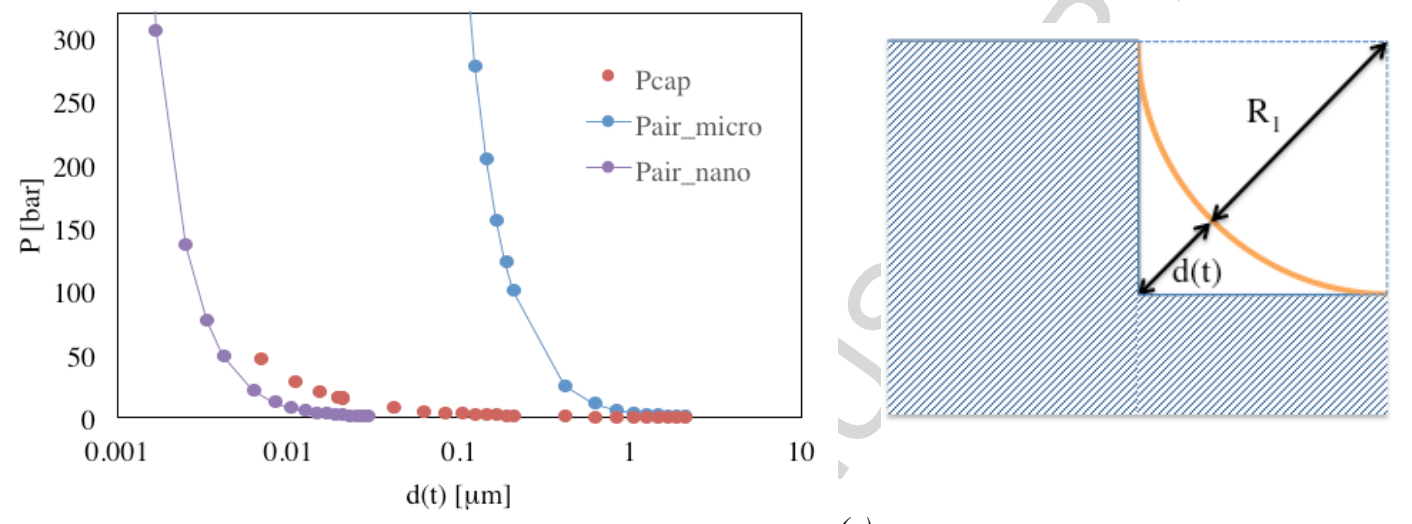

(a)

(b)

Figure 12 Capillary pressure (Pcap) and pressure due to the trapped air, for micro and nano-features (Pair), at $150^{\circ} \mathrm{C}$, versus the decrease of the filling distance $d(t)$ calculated from equation 6 and 4 respectively (a). A sketch of the feature is also reported (b).

Figure 12 shows that the effect of the trapped air can be significant. In particular, in the case of micro-features, for values of $\mathrm{d}(\mathrm{t})$ smaller than $1 \mu \mathrm{m}$, the pressure due to the trapped air increases very fast with the decrease of $\mathrm{d}(\mathrm{t})$. Surface tension has a negative effect on the pressure-driven flow (Kim et al., 2002), that is the case considered in this work. However, the effect of the capillary pressure is significant only if $\mathrm{d}(\mathrm{t})$ is smaller than $0.1 \mu \mathrm{m}$, therefore, it can be neglected for microfeature replication. If the filling pressure is comparable with the pressure due to the trapped air, the velocity of the polymer that fills the nickel insert corner is significantly reduced and corner filling time increases. The longer filling time coupled with a cavity surface temperature close to the crystallization temperature can induce the polymer solidification and, as a consequence, the nickel corner would not be filled completely.

As mentioned by Zhang et al (Zhang et al., 2012), the air trapped in the micro-feature aligned with the flow direction could escape, whereas, for the micro-features orthogonal to the flow direction this phenomenon is limited, this could explain the finding that the replication is more accurate in the direction of the flow.

For all the mentioned reasons, the increase of holding pressure levels is not sufficient to assure the complete filling of the nickel insert corner, if the material has enough time to crystalize, as it may 
be for the samples obtained with $\mathrm{T}_{\text {level }}=120^{\circ} \mathrm{C}$ higher holding pressure. To reduce the crystallization phenomenon, a further increase of cavity surface temperature, up to $150^{\circ} \mathrm{C}$ is necessary.

\section{Replication of nano-features}

The replication ability has been studied also for the nano-feature shown in Figure $1 \mathrm{~b}$.

Figure 13 shows some examples of AFM images of nano-features obtained on the iPP molded samples with $\mathrm{P}_{\mathrm{h}}=720$ bar, $\mathrm{T}_{\text {level }}=150^{\circ} \mathrm{C}$ and different heating times. Under these conditions, the shape of the edges is improved and the height of the features is enhanced by increasing the heating time.

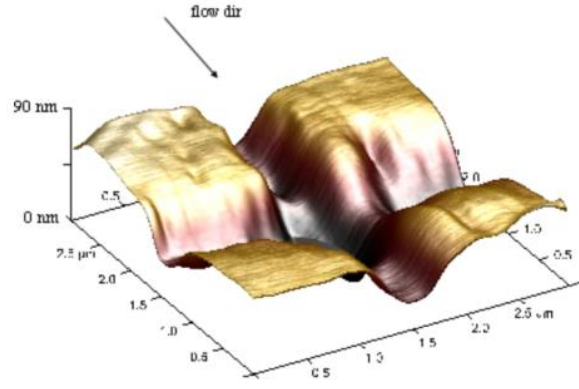

$150-1-720$

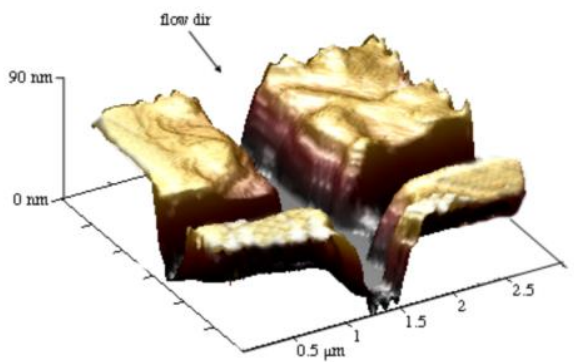

$150-1-720$

Figure 13 AFM height images of the nano-features on injection molded samples obtained with $T_{\text {level }}=150^{\circ} \mathrm{C}$ and $P_{h}=720$ bar in different conditions of heating time.

The values of percentage deviation of the feature height, $\mathrm{H}$, as defined in equation 2 , for samples obtained in different injection molding conditions (cavity surface temperature, heating time and holding pressure) are reported in Figure 14. 


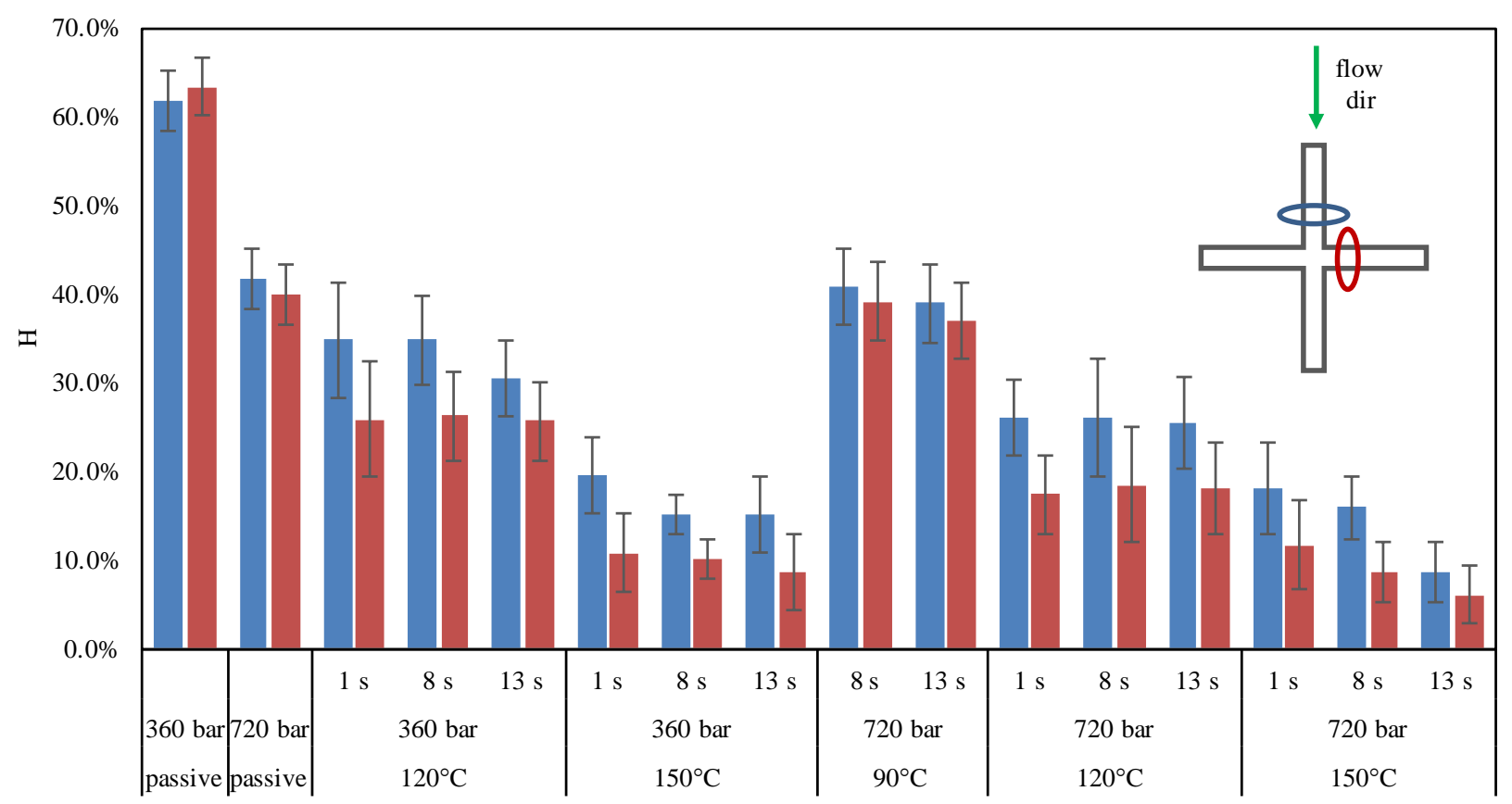

Figure 14 H index (equation 2) of nano-features in samples obtained as reported in Table 1. The H values are reported both for the nano-features aligned to the flow direction and for the nano-features orthogonal to it. A sketch of the AFM acquired areas is also reported.

Figure 14 shows that the flow direction has a certain influence on the replication accuracy, since the wings parallel to the flow direction presented a higher replication accuracy with respect to the wings orthogonal to flow direction, although, the differences are within the measurement confidence for the most of cases. The replication accuracy was very poor for the cases in which the heating devices were not activated (passive360 and passive720). In these cases, a holding pressure increase induced an enhancement in replication accuracy, as also observed for the micro-features. The increase of cavity surface temperature up to $90^{\circ} \mathrm{C}$ was not sufficient to reduce the $\mathrm{H}$ index, whereas a $\mathrm{T}_{\text {level }}=120^{\circ} \mathrm{C}$ induced a significant improvement of the replication ability. With this cavity surface temperature, a weak enhancement in replication, within the range of measure confidence, was achieved by increasing the holding pressure. A significant increase of replication accuracy has been obtained with $\mathrm{T}_{\text {level }}=150^{\circ} \mathrm{C}$; in this case, the $\mathrm{H}$ values are around $10 \%$. The heating time influenced the replication accuracy only for $\mathrm{T}_{\text {level }}=150^{\circ} \mathrm{C}$, indeed, with $\mathrm{P}_{\mathrm{h}}=720$ bar the $\mathrm{H}$ index became lower than $10 \%$.

All the findings suggest that the most important operating parameter that has to be controlled to achieve a high replication accuracy is the cavity surface temperature, as also observed for the replication of micro-features.

\section{Discussion on nano-feature replication}

Generally, the trends shown by the $\mathrm{H}$ index for nano-features, with respect to the holding pressure, the cavity surface temperature and the heating time, are similar to the trends observed for the 
FWHM index adopted for the micro-features. This confirms that the controlling phenomena are the same, independently on the size of the features.

However, in the replication of nano-features some additional phenomena can play a relevant role, namely the morphology developed close and on the molded surface that on its turn depends on the thermomechanical history experienced by the material.

The dimensions of the nano-features are of the same order of magnitude of the morphological structures typically found close to the surface of iPP injection molding samples (Housmans et al., 2009; Liparoti et al., 2017, 2016b). Figure 15 shows the AFM height and amplitude error images, acquired on a molding sample surface, obtained with $\mathrm{T}_{\text {level }}=150^{\circ} \mathrm{C}, \mathrm{t}_{\mathrm{h}}=13$ and $\mathrm{P}_{\mathrm{h}}=360 \mathrm{bar}$.
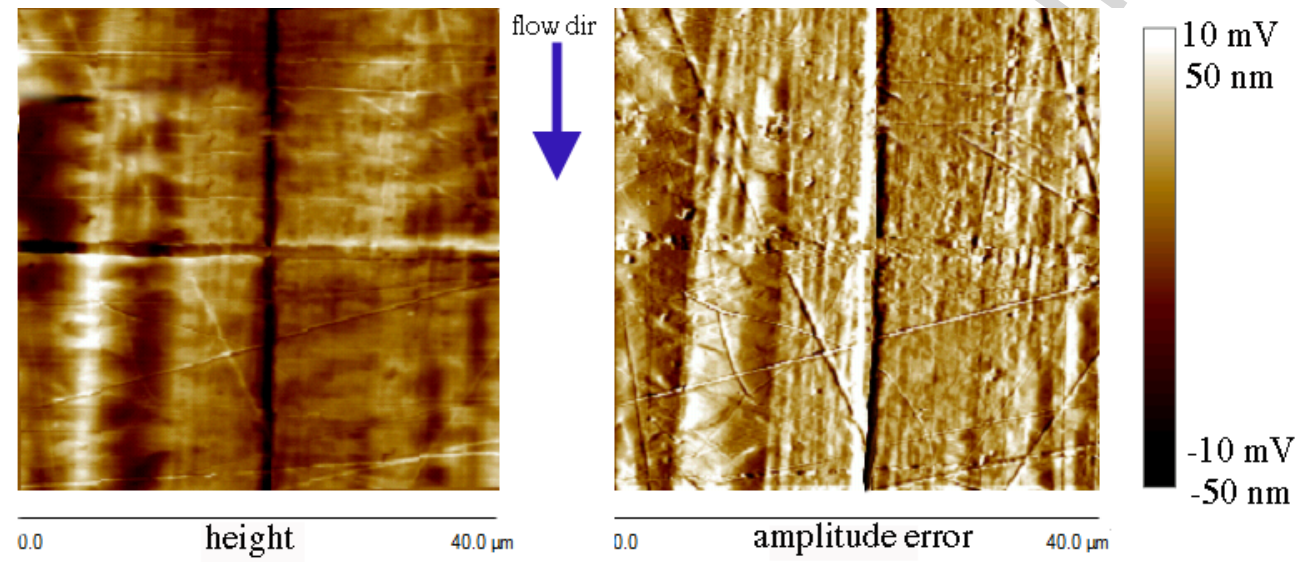

Figure 15 AFM height map and AFM amplitude error (from left to right) of the nano-feature on the sample obtained with $T l_{\text {evel }}=150^{\circ} \mathrm{C}, t_{h}=13 \mathrm{~s}$ and $P_{h}=360$ bar. The flow direction is also reported.

The elongated crystalline structures, aligned to the flow direction, are due to the organization of the polymer chains in fibrils and have thickness of about $200 \mathrm{~nm}$.

When the melt comes in contact with the feature, it is still amorphous, due to the high temperature; after the first contact, it starts to crystallize. This crystallization is influenced by the thermal history and by the flow field, that orients and stretches the molecular chains.

Figure 14 shows that the replication accuracy of nano-features is sensitive on the direction of wings with respect to the flow, in particular, the replication accuracy of wings parallel to the flow direction is higher with respect to the replication of wings orthogonal to the flow front. This can be due to the anisotropy of the morphology developed on the sample surface: in the direction parallel to the flow front, the fibrils are tightly packed around the feature, surrounding it; in the orthogonal direction, each fibril sees the feature as an obstacle and overtakes it. The growing and the consequent shrinkage of fibrils, which could be different with respect the flow direction, can induce an additional reduction of replication accuracy. This can explain the difference in replication accuracy with respect to the flow front (Pomerleau and Sanschagrin, 2006). 


\section{Conclusions}

In this work, the replication of micro and nano-features on a iPP, during the injection molding process, was experimentally analyzed. In particular, in order to enhance the replication quality, the cavity surface temperature was increased up to $150^{\circ} \mathrm{C}$ for times ranging from values slightly higher than the filling stage up to some seconds after the holding stage.

The replication quality was found to certainly improve by effect of an increase of surface temperature and, to smaller extent, by effect of an increase of the holding pressure. Most of the positive effects took place already after $1.3 \mathrm{~s}$ heating time; longer heating times gave rise to small additional improvements. The results are in line with the hypothesis that when the polymer encounters the micro-features, some air remains entrapped between the polymer and the microfeature corners. While the polymer fills those corners the trapped air is compressed and its pressure counteracts and delays the progression of the polymer. Consequently, the polymer decelerates and it might have time to crystallize, which would prevent further flow of the polymer toward the tip of the corner. The trapped air could partially escape when the feature is aligned along the flow direction, this may help the replication accuracy in the direction parallel to the flow front.

In the case of nano-feature replication, the capillary pressure has a more relevant role in replication accuracy. An additional phenomenon affecting the accuracy of replication can be due to the morphology developed on the molded surface. In particular, the fibrils that are detected on the molded surface have thickness in the range of nano-feature dimension and their orientation can influence the replication accuracy.

\section{References}

Attia, U.M., Marson, S., Alcock, J.R., 2009. Micro-injection moulding of polymer microfluidic devices. Microfluidics and Nanofluidics 7, 1-28. doi:10.1007/s10404-009-0421-x

Calaon, M., Hansen, H.N., Tosello, G., Garnaes, J., Nørregaard, J., Li, W., 2013. Microfluidic chip designs process optimization and dimensional quality control. Microsystem Technologies 21, 561-570. doi:10.1007/s00542-013-2025-3

Chen, S.-C., Lin, Y.-W., Chien, R.-D., Li, H.-M., 2008. Variable mold temperature to improve surface quality of microcellular injection molded parts using induction heating technology. Advances in Polymer Technology 27, 224-232. doi:10.1002/adv.20133

Coccorullo, I., Pantani, R., Titomanlio, G., 2003. Crystallization kinetics and solidified structure in iPP under high cooling rates. Polymer 44, 307-318. doi:10.1016/S0032-3861(02)00762-0

De Santis, F., Adamovsky, S., Titomanlio, G., Schick, C., 2006. Scanning Nanocalorimetry at High 
Cooling Rate of Isotactic Polypropylene. Macromolecules 39, 2562-2567. doi:10.1021/ma052525n

De Santis, F., Pantani, R., 2016. Development of a rapid surface temperature variation system and application to micro-injection molding. Journal of Materials Processing Technology 237, 1-11. doi:10.1016/j.jmatprotec.2016.05.023

Hoon, H., C G, P., C S, L., Y T, K., 2008. Engineering Plasticity and Its Applications From Nanoscale to Macroscale.

Housmans, J.-W., Gahleitner, M., Peters, G.W.M., Meijer, H.E.H., 2009. Structure-property relations in molded, nucleated isotactic polypropylene. Polymer 50, 2304-2319. doi:10.1016/j.polymer.2009.02.050

Jansen, K.M.B., Flaman, A.A.M., 1994. Construction of fast-response heating elements for injection molding applications. Polymer Engineering \& Science 34, 894-897.

Kalima, V., Pietarinen, J., Siitonen, S., Immonen, J., Suvanto, M., Kuittinen, M., Mönkkönen, K., Pakkanen, T.T., 2007. Transparent thermoplastics: Replication of diffractive optical elements using micro-injection molding. Optical Materials 30, 285-291. doi:10.1016/j.optmat.2006.11.046

Kamal, M.R., Isayev, A.I., Liu, S.-J., 2009. Injection molding : technology and fundamentals, in: Hanser (Ed.), Progress in Polymer Processing. Carl Hanser Verlag GmbH \& Co. KG, p. 737.

Kang, S., 2012. Micro/Nano Replication: Processes and Applications. John Wiley \& Sons, Inc., Hoboken, NJ, USA. doi:10.1002/9781118146965

Kim, D.S., Lee, K.-C., Kwon, T.H., Lee, S.S., 2002. Micro-channel filling flow considering surface tension effect. Journal of Micromechanics and Microengineering 12, 236-246. doi:10.1088/0960-1317/12/3/307

Kimerling, T.E., Liu, W., Kim, B.H., Yao, D., 2006. Rapid hot embossing of polymer microfeatures. Microsystem Technologies 12, 730-735. doi:10.1007/s00542-006-0098-y

Kooy, N., Mohamed, K., Pin, L.T., Guan, O.S., 2014. A review of roll-to-roll nanoimprint lithography. Nanoscale research letters 9, 320. doi:10.1186/1556-276X-9-320

Kuhn, S., Burr, A., Kübler, M., Deckert, M., Bleesen, C., 2010. Study on the replication quality of micro-structures in the injection molding process with dynamical tool tempering systems. Microsystem Technologies 16, 1787-1801. doi:10.1007/s00542-010-1104-y

Lee, W., Jin, M.K., Yoo, W.C., Lee, J.K., 2004. Nanostructuring of a polymeric substrate with welldefined nanometer-scale topography and tailored surface wettability. Langmuir 20, 76657669. doi:10.1021/la049411

Leech, P.W., 2008. Pattern replication in polypropylene films by hot embossing. Microelectronic 
Engineering 85, 181-186. doi:10.1016/j.mee.2007.05.002

Lin, H.L., Chen, S.C., Jeng, M.C., Minh, P.S., Chang, J.A., Hwang, J.R., 2012. Induction heating with the ring effect for injection molding plates. International Communications in Heat and Mass Transfer 39, 514-522. doi:10.1016/j.icheatmasstransfer.2012.02.009

Liparoti, S., Landi, G., Sorrentino, A., Speranza, V., Cakmak, M., Neitzert, H.C., 2016a. Flexible Poly(Amide-Imide)-Carbon Black Based Microheater with High-Temperature Capability and an Extremely Low Temperature Coefficient. Advanced Electronic Materials 2, 1600126. doi:10.1002/aelm.201600126

Liparoti, S., Sorrentino, A., Guzman, G., Cakmak, M., Titomanlio, G., 2015. Fast mold surface temperature evolution: relevance of asymmetric surface heating for morphology of iPP molded samples. RSC Advances 5, 36434-36448.

Liparoti, S., Sorrentino, A., Speranza, V., Titomanlio, G., 2017. Multiscale mechanical characterization of iPP injection molded samples. European Polymer Journal 90, 79-91. doi:10.1016/j.eurpolymj.2017.03.010

Liparoti, S., Sorrentino, A., Titomanlio, G., 2016b. Fast cavity surface temperature evolution in injection molding: control of cooling stage and final morphology analysis. RSC Advances 6, 99274-99281. doi:10.1039/C6RA22968A

Lucchetta, G., Fiorotto, M., Bariani, P.F., 2012. Influence of rapid mold temperature variation on surface topography replication and appearance of injection-molded parts. CIRP Annals Manufacturing Technology 61, 539-542. doi:10.1016/j.cirp.2012.03.091

Marinello, F., 2007. Atomic force microscopy in nanometrology: modeling and enhancement of the instrument. Techinical university of Denmark. PhD thesis.

Masato, D., Sorgato, M., Lucchetta, G., 2016. Analysis of the influence of part thickness on the replication of micro-structured surfaces by injection molding. Materials \& Design 95, 219224. doi:10.1016/j.matdes.2016.01.115

Matschuk, M., Larsen, N.B., 2013. Injection molding of high aspect ratio sub-100 nm nanostructures. Journal of Micromechanics and Microengineering 23, 25003. doi:10.1088/0960-1317/23/2/025003

Menotti, S., Hansen, H.N., Bissacco, G., Calaon, M., Tang, P.T., Ravn, C., 2014. Injection molding of nanopatterned surfaces in the sub-micrometer range with induction heating aid. The International Journal of Advanced Manufacturing Technology 74, 907-916.

Mosaddegh, P., Angstadt, D.C., 2008. Micron and sub-micron feature replication of amorphous polymers at elevated mold temperature without externally applied pressure. Journal of Micromechanics and Microengineering 18, 35036. doi:10.1088/0960-1317/18/3/035036 
Pantani, R., Speranza, V., Titomanlio, G., 2014. Evolution of iPP Relaxation Spectrum during Crystallization. Macromolecular Theory and Simulations 23, 300-306. doi:10.1002/mats.201300147

Park, S.H., Yoo, Y.-E., Lee, W., 2016. Effect of a pressurized cavity on the replication of micropatterns with injection molding. e-Polymers 16, 351. doi:10.1515/epoly-2016-0061

Pomerleau, J., Sanschagrin, B., 2006. Injection molding shrinkage of PP: Experimental progress. Polymer Engineering \& Science 46, 1275-1283. doi:10.1002/pen.20595

Rytka, C., Opara, N., Andersen, N.K., Kristiansen, P.M., Neyer, A., 2016. On The Role of Wetting, Structure Width, and Flow Characteristics in Polymer Replication on Micro- and Nanoscale. Macromolecular Materials and Engineering 301, 597-609. doi:10.1002/mame.201500350

Saito, T., Satoh, I., Kurosaki, Y., 2002. A new concept of active temperature control for an injection molding process using infrared radiation heating. Polymer Engineering \& Science 42, 2418 2429. doi:10.1002/pen.11128

Sato, K., Hayashi, K., Saito, T., Kurosaki, Y., n.d. Straightening of warped products assisted by near-infrared radiation, in: Advances in Electronic Materials and Packaging 2001 (Cat. No.01EX506). IEEE, pp. 347-352. doi:10.1109/EMAP.2001.984008

Schift, H., David, C., Gabriel, M., Gobrecht, J., Heyderman, L.J., Kaiser, W., Köppel, S., Scandella, L., 2000. Nanoreplication in polymers using hot embossing and injection molding. Microelectronic Engineering 53, 171-174. doi:10.1016/S0167-9317(00)00289-6

Shao, P.E., van Kan, A., Wang, L.P., Ansari, K., Bettiol, A.A., Watt, F., 2006. Fabrication of enclosed nanochannels in poly(methylmethacrylate) using proton beam writing and thermal bonding. Applied Physics Letters 88, 93515. doi:10.1063/1.2181631

Sorrentino, A., Pantani, R., 2013. Determination of the effect of pressure on viscosity of an isotactic polypropylene. Polymer Bulletin 70, 2005-2014. doi:10.1007/s00289-013-0913-4

Stormonth-Darling, J.M., Saeed, A., Reynolds, P.M., Gadegaard, N., 2016. Injection Molding Micro- and Nanostructures in Thermoplastic Elastomers. Macromolecular Materials and Engineering 301, 964-971. doi:10.1002/mame.201600011

Surace, R., Trotta, G., Bellantone, V., Fassi, I., 2012. The micro injection moulding process for polymeric components manufactoring TURING, in: Constantin, V. (Ed.), New Technologies Trends, Innovations and Research. InTech, p. 65. doi:10.5772/35299

Tan, G., Inoue, N., Funabasama, T., Mita, M., Okuda, N., Mori, J., Koyama, K., Kaneko, S., Nakagawa, M., Matsuda, A., Yoshimoto, M., 2014. Formation of 0.3-nm-high stepped polymer surface by thermal nanoimprinting. Applied Physics Express 7, 55202. doi:10.7567/APEX.7.055202 
Velten, T., Bauerfeld, F., Schuck, H., Scherbaum, S., Landesberger, C., Bock, K., 2011. Roll-to-roll hot embossing of microstructures, in: Microsystem Technologies. pp. 619-627. doi:10.1007/s00542-010-1158-x

Yang, C., Huang, H.-X., Castro, J.M., Yi, A.Y., 2011. Replication characterization in injection molding of microfeatures with high aspect ratio: Influence of layout and shape factor. Polymer Engineering \& Science 51, 959-968. doi:10.1002/pen.21914

Yao, D., 2002. Injection molding high aspect ratio microfeatures. Journal of Injection Molding Technology 6, 11 .

Yao, D., Kimerling, T.E., Kim, B., 2006. High-frequency proximity heating for injection molding applications. Polymer Engineering \& Science 46, 938-945. doi:10.1002/pen.20548

Yoshii, M., Kuramoto, H., Ochiai, Y., 1998. Experimental study of the transcription of minute width grooves by injection molding (II). Polymer Engineering \& Science 38, 1587-1593. doi:10.1002/pen.10329

Yu, M.C., Young, W.B., Hsu, P.M., 2007. Micro-injection molding with the infrared assisted mold heating system. Materials Science and Engineering A 460-461, 288-295. doi:10.1016/j.msea.2007.02.036

Zhang, J., Sahli, M., Gelin, J.-C., Barrière, T., 2015. Roll manufacturing of polymer microfluidic devices using a roll embossing process. Sensors and Actuators A: Physical 230, 156-169. doi:10.1016/j.sna.2015.03.002

Zhang, N., Chu, J.S., Byrne, C.J., Browne, D.J., Gilchrist, M.D., 2012. Replication of micro/nanoscale features by micro injection molding with a bulk metallic glass mold insert. Journal of Micromechanics and Microengineering 22, 65019. doi:10.1088/0960-1317/22/6/065019

Zhou, M., Jiang, B., Weng, C., Zhang, L., 2017. Experimental study on the replication quality of micro-nano cross-shaped structure arrays in injection molding. Microsystem Technologies 23, 983-989. doi:10.1007/s00542-016-2819-1 

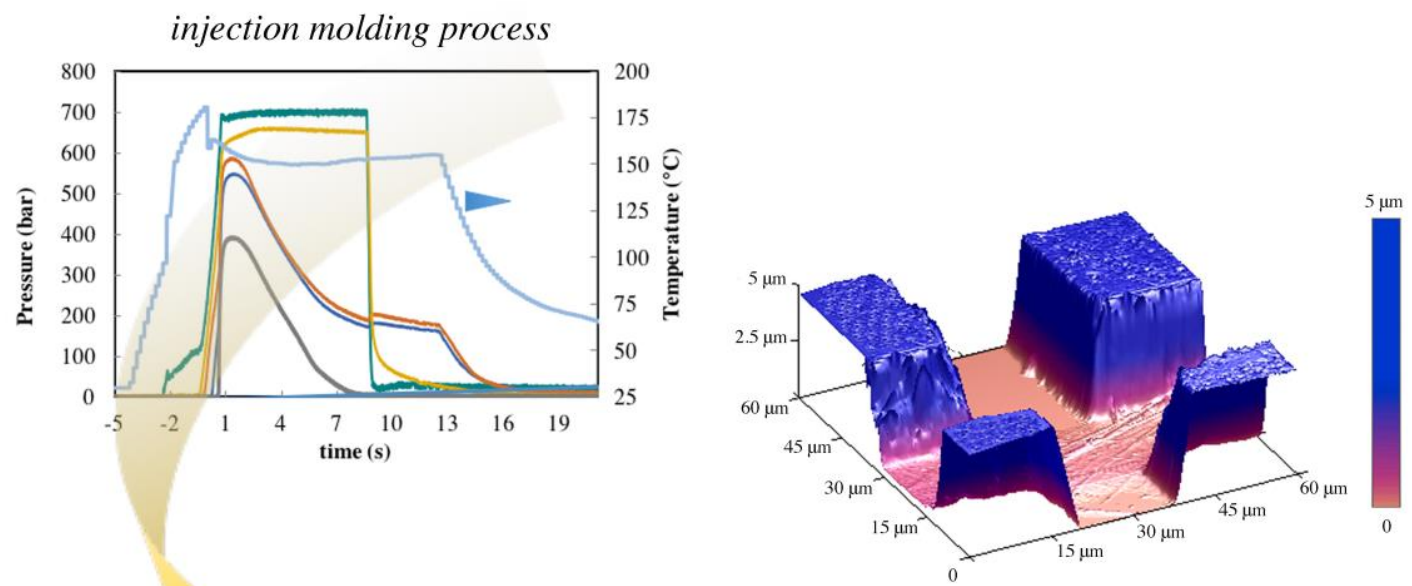

Fast control of cavity

accurate replication of micro and nano-features surface temperature on semicrystalline polypropylene

Graphical abstract 


\section{Highlights}

- Micro and nano-structured surface realized by injection molding of semi-crystalline polymer with fast control of mold surface temperature.

- Packing pressure increase enhances the replication ability.

- Cavity surface temperature increase is more effective with respect packing pressure in enhancing the replication accuracy.

- Surface tension play a significant role in replication of nano-structures. 